\title{
Tenés el mate lleno de infelices ilusiones: la estrategia de inserción internacional del gobierno de Macri (2015-2019)
}

\author{
Alejandro Simonoff ${ }^{1}$
}

La estrategia internacional de Cambiemos se presentó como "un giro de 180 grados" con respecto a la llevada adelante por Cristina Fernández, ya que priorizó los vínculos con los países de la tríada occidental² (Cué y Jiménez, 2015: 4) y se bosquejó como una construcción "globalista" ${ }^{3}$, para usar la conceptualización de Amado Cervo (Cervo, 2003). Aunque las dos tendencias de esa corriente conviven dentro del gobierno de Macri (la benigna, que acepta la globalización y sus reglas, sin la más mínima confrontación con ella; y otra asimétrica, la cual, a pesar de reconocer sus dificultades, busca participar de las instituciones para influenciar en las normas que emergen y lograr ciertos objetivos), resulta clara una preponderancia de la primera.

Es indudable que el sistema internacional puede generar oportunidades para el país, pero para que ello fuera posible es necesario tener tanto un diagnóstico preciso del mundo, como también una determinación de los intereses en juego. La primera cuestión no ha sido una fortaleza del gobierno de Cambiemos, que tiene por un lado una visión del mundo desfasada temporalmente, ya que, por un lado, opera como si estuviéramos en los comienzos de la posguerra fría, cuando el modelo neoliberal se erigía como una promesa -más cargada de deseos que de realidades-, escenario muy diferente al del momento actual, el que se encuentra atravesado por una crisis profunda (Simonoff, 2019b); y, por otro, cuando el Presidente habla del "mundo" en realidad se refiere principalmente a la comunidad financiera y bursátil más que al conjunto de las unidades políticas que lo conforman y los diversos planos con que ellas se vinculan.

Doi: https://doi.org/10.24215/23142766e081

${ }^{1}$ Profesor Titular Ordinario de Historia General VI (UNLP) y Profesor Titular de Política Exterior Argentina (UCALP). Investigador del IdHCS e IRI (UNLP), Profesor del Doctorado y la Maestría en Relaciones Internacionales, IRI-UNLP, La Plata, Argentina, asimonoff2010@gmail.com

${ }^{2}$ Nos referimos al núcleo conformado por Estados Unidos, la Unión Europea y Japón como unidades decisorias y a los organismos multilaterales de crédito como los brazos ejecutores del proyecto neoliberal global desde el fin de la Guerra Fría.

${ }^{3}$ Tras el fin del mundo bipolar, los occidentalistas que promocionaban un alineamiento irrestricto con Washington en la Guerra Fría, se transformaron en globalistas, quienes, como apuntó Amado Cervo, "deducen de la práctica, de extraer conceptos a veces elaborados por hombres de Estado, a veces implícitas en su práctica." (Cervo, 2003, 6) 
Producto de esa perspectiva existe una externalización de lo que se considera intereses propios, los que se constituyen por lo que el "mundo" espera de la Argentina, y no al revés, llevado a una escasa o nula determinación de ellos. Como apuntó Cervo:

los intereses nacionales se diluyen en el orden creado por el multilateralismo de las relaciones internacionales, la llamada gobernanza global. La política exterior se convirtió en concepto fuera de moda, mero adorno de la acción del Estado, ya que no se le asignaba más la realización de intereses concretos (2003: 18).

Esto se observó en el peligroso aumento de la vulnerabilidad el país, como lo informó la agencia Bloomberg. ${ }^{4}$ Asumiendo el modelo de inserción, los rasgos señalados por Jonathan Joseph de ser:

una versión moderna del desarrollo combinado y desigual, en la medida en que están encerrados en las condiciones sociales de su propio estadio de desarrollo, pero están sujetos a las estrategias y técnicas de los países liberales avanzados que dominan las actividades de las principales organizaciones de desarrollo. Se necesitaría una gran imaginación para creer que, en estos casos, estas organizaciones logran promover la salud, la riqueza y el bienestar de las poblaciones a través de técnicas liberales avanzadas de gobierno a distancia a través de la libertad y la autonomía de los actores individuales responsables (Joseph, 2011: 59).

A pesar de estas dificultades, esta estrategia ha sido adjetivada como "inteligente" por el Presidente, en contraposición a lo que consideró "una etapa de confrontación" (Macri, 2019). Más allá del sesgo maniqueo y erróneo con el que caracteriza a la fase previa, esta autoponderación fue precisada por su canciller, Jorge Faurie, quien la entiende como:

una política exterior abierta y centrada en nuestros intereses que -sin condicionantes ideológicos pero comprometida con la democracia, los derechos humanos y el multilateralismo- consolide la presencia de la Argentina en el mundo, capitalice la relación con cada uno de los países en los que exista una oportunidad, multiplique las alternativas para lleva nuestros productos a nuevos mercados y profundice el acceso a los ya conquistados (Faurie, febrero 2018: 19).

Presentada de un modo menos sistemático, sin los pilares ni los esquemas de círculos concéntricos que fueran esbozados por su antecesora ${ }^{5}$, y arrastrando el mismo defecto, el

\footnotetext{
${ }^{4}$ Según lo informado por Página/12, la Agencia Bloomberg presentó un ranking de países emergentes, donde la Argentina resulta una de los más vulnerables a partir de cinco factores (relación deuda externa de corto plazo sobre el PBI, 40,5\%; gran desviación entre la meta fijada por el gobierno y la real, 35.8; baja cantidad de reservas de cobertura, $85.9 \%$; déficit de cuenta corriente en relación con el $\mathrm{PBI}, 2 \%, \mathrm{y}$; mal resultado de ítem efectividad del gobierno, 0,16) (Página/12, 26 julio de 2019: 2-3)

${ }^{5}$ La Ingeniera Susana Malcorra, la primera canciller macrista, estableció una serie de pilares - eliminación de la pobreza, lucha contra el narcotráfico y el terrorismo, y establecimiento de mecanismos institucionales- y una estructura de círculos concéntricos: el primero de ellos "nuestro vecindario", son quienes "están alrededor"; el siguiente está compuesto por las relaciones con Estados Unidos, Europa, China y Rusia, y finalmente, el tercero formado por África y el mundo árabe (HSN, 2016: 2-3). Pero, a pesar de su claridad expositiva y su inclinación hacia un globalismo asimétrico, a poco de andar se evidenciaron contradicciones entre esa estructura y sus pilares por el realineamiento con la tríada occidental, cierto desdén, para llamarlo de algún modo,
} 
de erigirse como una práctica instrumental y no ideológica -cuando dista de poseer esos atributos-, la postura aparece como menos ambiciosa, más flexible y permeable al núcleo duro presidencial. ${ }^{6}$

El gobierno argentino tomó como dato cierto el discurso sobre la extensión de la democracia de libre mercado, cuyo resultado sería un mundo sin conflictos (Fukuyama, 1990: 22). Sin embargo, no sólo vivimos en un mundo peligroso y caótico, sino que la promesa de bienestar general también resultó trunca, ya que, como señaló Dani Rodrik, quienes siguieron esa receta a puntillas hasta el crack de las Subprime no obtuvieron los resultados esperados:

Hubo éxitos fanáticos en este periodo, concretamente en China y la India. Pero, como veremos, estos países eligieron jugar al juego de la globalización no con las reglas nuevas, sino con las de Bretton Woods. En lugar de abrirse de forma incondicional al comercio y a las finanzas internacionales, adoptaron estrategias mixtas con una fuerte dosis de intervencionismo para diversificar sus economías. Mientras los países que habían seguido recetas más convencionales -como los de Latinoamérica- languidecían (Rodrik, 2011: 19).

A ello hay que sumarle, los efectos de la crisis de 2008, el ascenso de fórmulas extremistas en el mundo periférico y central, y las guerras contra el terrorismo y por la supremacía económica, aspectos que cuestionan aún más fuertemente esa ilusión.

\section{El Aislamiento}

Para afianzar esta estrategia debió considerar a la llevada adelante por el kirchnerismo como aislacionista. Como acertadamente indicaron Mario Rapoport y Claudio Spiguel para la fase de la Guerra Fría, la llegada de las políticas autonómicas y el consiguiente abandono de las políticas occidentalistas comenzaron a vincular aquellas con el aislamiento (Rapoport y Spiguel, 2003: 183-184).

Las estrategias que confrontaban en algún plano con Washington fueron consideradas como desafíos al alineamiento occidental, cuando en realidad resulta lógico que los países disputasen entre sí, ya que representan intereses diversos. ${ }^{7}$

Anabella Busso ha desarrollado una aproximación al concepto de aislamiento, caracterizándolo como producto de una lectura simplista y politizada que resulta rígida, ya que puede no describir situaciones precisas (Busso, 2017).

por los poderes emergentes (China, Rusia, los BRICS), la instrumentalización del Mercosur como una escala para el Acuerdo de Libre Comercio con la Unión Europea y su desplazamiento de la prioridad hacia la Alianza del Pacífico; y a través de ellos, llegar a los TTP y TTIP.

${ }^{6}$ La Canciller tenía su propia agenda definida por su deseo de acceder a la Secretaría General de Naciones Unidas, y eso llevó a que el Gobierno morigere muchas de sus posiciones internacionales, como la de Venezuela, por ejemplo, a favor de un sesgo de globalismo asimétrico. Fue ese el principal catalizador de la disputa con el núcleo duro presidencial, más próximo al benigno y no los "motivos personales" esgrimidos inicialmente por la Ingeniera la cuestión que motivó su renuncia. (Página/12, 17 junio 2019)

${ }^{7}$ La cuestión está en el grado de esa confrontación, cosa que no fue nunca ni determinada ni aclarada debidamente por los impugnadores. 
Nosotros pensamos que desde la crisis de 2001 existió un diseño de nuestra política externa que se desplegó sobre una estructura triangular, con Estados Unidos y Brasil en varios ejes: multilateralización de la agenda de seguridad, prioridad regional, modelo de inserción y desarrollo, tratamiento de la deuda y cuestión Malvinas, que funcionó hasta la llegada de la crisis de 2008 (Simonoff, 2012). Tras ella el funcionamiento sinérgico comenzó a fallar e hizo necesaria una nueva estrategia que incorporaba a otro actor que comenzaba a ser relevante: China. Por ese motivo, la decisión de firmar la Asociación Estratégica Integral, aunque no exenta de contradicciones ${ }^{8}$, resultó ser el cambio más significativo de nuestro relacionamiento externo desde 1983, ya que reemplazó el triángulo en el que se encontraba inmersa por un rombo (Busso, Actis y Novello, 2017).

La caracterización de la política exterior del kirchnerismo como aislacionista es de larga data (Simonoff, 2016), aunque durante la campaña presidencial de 2015 ésta se intensificó, como lo mostró el documento titulado "Reflexiones sobre los desafíos externos de la Argentina". Este fue firmado por académicos y burócratas vinculados a temas internacionales que representaron a varios partidos políticos (Pro, el Frente Renovador, la UCR y el peronismo disidente). En él se señaló la necesidad de una participación en los procesos de integración económica y política, cosa que el país había venido haciendo en la UNASUR, la CELAC o el G20, por ejemplo. Pero la disidencia está en el modo, este manifiesto expresa claramente un sesgo globalista, ya que según estas visiones "quienes no participan en su construcción, quedarán sumidos en situación de aislamiento y gradual irrelevancia" (Grupo Consenso, 2015).

¿Cuáles son los parámetros del aislamiento para el gobierno de Cambiemos? Ellos han sido por lo menos confusos. Pasado los primeros días del nuevo gobierno argentino, Mauricio Macri tituló en su cuenta de Facebook "Terminamos con el aislamiento" con una fotografía junto a François Holande en su visita a Argentina, como una muestra del nuevo paradigma de relacionamiento externo (El Día, 2016). Sin embargo, cabe recordar que esa visita del mandatario francés se postergó un año, debido a que cuando estaba prevista se produjeron los atentados de París, con lo cual el mandatario galo debió suspender su agenda externa, y no a un rechazo al gobierno anterior. También en una visita a la Provincia de Chaco insistió en calificar la situación del país como "uno de los tres países más aislados" del mundo. Aunque no sabemos de dónde sacó ese dato, si nos permitió entrever qué entiende por aislamiento y que éste se vincula con "la aplicación de pautas proteccionistas" (Clarín, 29 septiembre 2017: 10).

\section{El "mundo" en clave macrista}

Y cuál es el "mundo" que vislumbra el tandilense, tras la corrida cambiaria de 2018 dijo:

El mundo nos ha dado un apoyo inédito. Nunca en la historia le dieron un crédito tan grande a un país como el que le dieron a la Argentina. El mundo dice queremos que Argentina vaya por un camino de la normalización, que sea un jugador serio, un protagonista serio del mundo que viene, proveyendo alimentos, energía, tecnología. Si continuamos en esta tarea de ser

\footnotetext{
${ }^{8}$ El discurso industrialista de los gobiernos kirchneristas con la firma de este acuerdo chocó con el rol de proveedor de materias primas y los límites que esta relación le impuso a aquellos deseos.
} 
confiables, previsibles, el mundo va a seguir confiando y va a venir con más fuerza (Clarín, 25 abril 2018: 5).

Esta definición se ajusta a la externalización señalada por Cervo, pero también resulta imprecisa, ya que el "mundo" no es un actor, sino una representación sesgada que el gobierno construye de él.

En la comparecencia en la Comisión de Relaciones Exteriores de la Cámara de Diputados de la Nación, el canciller Faurie definió un ensayo de cuantificación del acceso al "mundo":

En lo que al comercio exterior respecta, cabe destacar que solamente el 20 por ciento de nuestro PBI está en contacto con el mundo. En otros países, como Chile, ese porcentaje llega al 48 por ciento; en México, al 73 por ciento, y el promedio mundial es de alrededor del 50 por ciento. Por lo tanto, todavía tenemos un déficit que debemos colmatar, y es un esfuerzo muy grande el que debemos realizar (HCD, 2018: 5).

La relación entre el comercio y el PBI, según el Banco Mundial, si lo comparamos con el promedio global y local para 2015, rondó en un $44 \%$ y, si lo comparamos con el de la región, en un 84\%; mientras para la gestión de Cambiemos esos porcentajes dan un $48 \%$ y $56 \%$ para 2016, un $44 \%$ y 54\% para 2017, y 53\% y 59\% para 2018 (Banco Mundial, 2019) ${ }^{9}$.

El mejor número de los últimos veinte años entre exportaciones y PBI fue en el 2002 $(35,447)$ y el de la administración de Cambiemos $(24,507)$ de 2018 , los que obedecen a un derrumbe de los factores domésticos del PBI y no al crecimiento de ventas al "mundo". EI promedio de los doce años del kirchnerismo fue 30,426, para la última gestión de Cristina Fernández 24,865 y de la gestión de Macri 21,483 (Banco Mundial, 2019).

Esta estrategia de inserción tiene sus bases materiales en el impulso de un modelo de exploración de materias primas, donde el sistema del agro-negocio sojero es su principal estrella, acompañado por el extractivismo minero ${ }^{10}$. Para el Presidente, esta elección se basó en el "potencial para ganar lugar en los supermercados del mundo" (Macri, 2017).

Ello no se reflejó en el comercio exterior argentino, ya que si bien las exportaciones crecieron de 113 mil millones de dólares en 2016 a 127 en 2018 (aumentaron un 12\%), en el primer semestre de 2019 tuvieron una baja del 16\%, con un déficit acumulado de 10.134 millones de dólares (se multiplicó por cinco) (INDEC, 2019). Según André Wainer y Paula Belloni:

Si bien el deterioro del balance comercial se venía dando desde el 2013, la derogación de las regulaciones cambiarias (el denominado "cepo") junto con la apertura comercial dispuesta por el gobierno de Cambiemos -en el marco grandes conflictos comerciales y crecientes medidas proteccionistas por parte de las principales potencias mundiales- no lograron incrementar las exportaciones y, por el contrario, produjeron un aumento en la elastici-

\footnotetext{
${ }^{9}$ Los datos son claros, la región tomaba distancia de la globalización, mientras la Argentina se acercaba de manera oscilante.

${ }^{10}$ La minería ya gozaba de importantes ventajas desde la administración de Cristina Fernández de Kirchner.
} 
dad ingreso de las importaciones, dando lugar a uno de los déficits comerciales más grandes de nuestra historia en 2017: -8309 millones de dólares (Wainer y Belloni, 2019: 4-5).

Además, se observó un proceso de "reprimarización" de las exportaciones, ya que entre 2015 y 2018 los productos de origen agropecuario pasaron de 12,9 a 21,2 (primer semestre de $2019,26,6 \%$ ) y las manufacturas de origen industrial se contrajeron de 39,5 a 32,4 (28,8\% en aquél lapso), cuyo desempeño se reflejó en una contracción del PBI y un crecimiento de la pobreza (INDEC, 2019). El aumento de las importaciones:

no estuvo dado centralmente por un incremento en la actividad manufacturera -históricamente dependiente de la compra de insumos y bienes de capital al exterior-, sino que adquirió un peso creciente la importación de bienes de consumo final (incluidos los automóviles), las cuales pasaron de representar el 18,0 por ciento de la estructura importadora en 2010-2015 al 21,7 por ciento en 2016-2018. Ello, en un contexto recesivo o de bajo crecimiento implicó el reemplazo de producción local por extranjera, y en consecuencia una importante destrucción de puestos de trabajo (Wainer y Belloni, 2019: 4).

Por otra parte, no solo se redujo y primarizó el comercio internacional con respecto al $\mathrm{PBI}$, sino que, según la Consultora DNI, entre 2006 y 2018 disminuyó la cantidad de empresas exportadoras, que pasaron de unas 15.000 a unas 5.890 (México: 30.000, Brasil: 20.000; Chile y Perú: aproximadamente 8.000), de las cuales 15 aceiteras y 5 automotrices concentran el $50 \%$ de las ventas (Lamiral, 2018).

\section{Principios del accionar externo}

Macri, en su último discurso en Nueva York ante la Asamblea General de las Naciones Unidas, invocó una serie de principios de matriz neoinstitucionalista que guiaron su accionar externo: "Durante estos años la Argentina también ha afianzado su rol positivo para fortalecer la paz y seguridad internacionales, contribuyendo en materia de usos pacíficos de la energía nuclear, desarrollo espacial, lucha contra el terrorismo y combate al crimen organizado trasnacional, entre otras" (Macri, 2019).

La securitización de la agenda internacional había llevado a los gobiernos argentinos desde la crisis de 2001 a evitar compromisos directos con la política de Washington. Al respecto de la administración de Cambiemos, es uno de los tres pilares que la sostuvieron inicialmente: "está totalmente en línea con algunas de las prioridades que el mundo tiene en estos días, tanto en términos de seguridad, como a la eliminación de los grupos extremistas en el mundo" (Malcorra, 2016).

Como parte de ello, en la visita de Obama a Buenos Aires en 2016, desde Washington se informó:

Estados Unidos y Argentina se comprometieron en trabajar juntos para combatir al crimen organizado y el tráfico de drogas. Estados Unidos ayudará a desarrollar la capacidad de autoridades del orden público de Argentina, lo que incluye la asistencia del Departamento de Justicia con relación 
al terrorismo y al financiamiento del terrorismo en la región de la Triple Frontera (OPS, 2016: 11).

Como producto de esta vinculación en estos temas, el gobierno argentino avanzó desdibujando la línea que separaba la seguridad interior de la defensa, como se devela claramente del análisis de Martín Di Natale (2016).

De todos los temas resaltados por el Presidente, tomamos la lucha contra el terrorismo, el cual se asentó en dos cuestiones. La primera fue la utilización del linkage con los atentados de los años noventa, como lo había hecho el kirchnerismo hasta la firma del Memorándum con Irán en 2013, pero ajustando esta agenda a la de los sectores más reaccionarios de Washington y Tel Aviv"11. Y, en segundo lugar, se centró en fortalecer "el intercambio de información y las medidas para prevenir su financiamiento" (Macri, 2019).

Con respecto ese uso, y como sostuvieron Ginsberg y Gitter en una nota de opinión en el diario Clarín, el gobierno de Cambiemos no profundizó la investigación y asumió que el esclarecimiento del atentado de la AMIA era a través de la llamada pista iraní, aunque para las pruebas judiciales es sólo "una hipótesis": "Mientras los jueces reconocieron -aun de manera limitada- el compromiso del Estado nacional y sus funcionarios en el atentado, el Gobierno se pasea en eventos internacionales reclamando Justicia, pero no se propone esclarecer nada" (Ginsberg y Gitter, 2019: 23).

La segunda cuestión se vio en la firma de un Decreto por el presidente Mauricio Macri para la creación del Registro Público de Personas y Entidades Vinculadas a Actos de Terrorismo y su financiamiento (RePET), que permitió al gobierno argentino, alineándose con Estados Unidos, Israel y el Reino Unido, declarar a Hezbollah como una organización de ese tipo y cambiar así la posición que hasta entonces había tenido Buenos Aires, ya que se salió "del listado que dicta Naciones Unidas y en el que no figura Hezbollah. Más allá del registro, la movida posiciona a Argentina claramente en un cambo en el conflicto de Medio Oriente, en lugar de conservar un lugar neutral y de impulso de la paz en esa región" (Kollman, 2019: 2) ${ }^{12}$.

No fue casual que la firma de esta norma se hiciera en las vísperas de la llegada del titular del Departamento de Estado, Mike Pompeo, quien reforzó esta situación anunciando una recompensa por Salman Raouf Salman, considerado el jefe de la célula terrorista que habría organizado la explosión en el edificio de la calle Pasteur hace más de dos décadas (Perfil, 20 julio 2019: 16).

\section{Estados Unidos: relaciones carnales reloaded}

A pesar del rechazo de la Ingeniera Malcorra de las "relaciones carnales" de los años noventa (Malcorra, 2016), el acercamiento a Washington en la agenda de seguridad por los

\footnotetext{
11 Una muestra de ello fue que, con motivo de la visita del Premier Benjamín Netanyahu, el embajador de Israel en Buenos Aires, Ilan Sztulman, señaló que "Nunca tuvimos una relación tan cercana como tenemos hoy con la administración del presidente Macri". (Perfil, 11 septiembre 2017: 8)

12 Una muestra de ello fue el tuit de John Bolton, el neoconservador consejero de seguridad nacional de Trump hasta septiembre de 2019, quien no dudo en celebrar esta firma como un paso más "en nuestros esfuerzos conjuntos para cortar el financiamiento de Hezbollah, y la capacidad de Irán de planificar ataques terroristas" (Perfil, 20 julio 2019: 16).
} 
temas de terrorismo y narcotráfico, como en la económica por la apertura, desregulación y reendeudamiento, se le parece bastante.

En este último plano, las reformas impulsadas recibieron en reiteradas oportunidades múltiples gestos de aprobación, como se observó en la declaración de la Oficina de Prensa de la Casa Blanca durante la visita de Obama a Buenos Aires:

Macri ha implementado reformas económicas de forma rápida para comenzar a abordar desequilibrios económicos y profundizar la integración de la economía mundial. Para apoyar estos esfuerzos los dos anunciaron pasos para reforzar el comercio y los gobiernos anunciaron pasos para reforzar el comercio y las inversiones, profundizarán la cooperación con el G 20 y promover su objetivo compartido del G 20 para un crecimiento económico sólido, sustentable y equilibrado (OPS, 2016: 11).

Como indicó Aldo Ferrer, este tipo de alabanzas "son un espejismo. Son los mismos aplausos que en su momento festejaron a los ministros responsables de las políticas de la dictadura y la década del 90" (Ferrer, 2016: 7). Sobre todo, por las consecuencias de estas medidas: "Si la estrategia neoliberal avanza hasta sus últimas consecuencias, como en el pasado, se produciría una severa limitación de la autonomía de la política económica, subordinada a las condicionalidades externas y las preferencias de grupos con posiciones dominantes en el mercado interno" (Ferrer, 2016: 7).

Por otro lado, el error del gobierno de Macri de apostar abiertamente por los demócratas, cuando el escenario electoral era incierto, y sus declaraciones posteriores, como en muchos aspectos de nuestra política exterior, están guiados más por deseos que por la comprobación empírica.

La estrategia de Trump llevó al abandono de algunos instrumentos multilaterales promocionados por Obama, como el TPP o TIPP ${ }^{13}$, e incluso a revisar el NAFTA o la OMC, con lo que se observó un retorno a mecanismos bilaterales, donde las asimetrías fueron reforzadas.

El triunfo del republicano no varió la situación estructural de "bifurcación" con China (Arrighi, 2007) ${ }^{14}$, sino que su giro hacia una política más proteccionista y unilateral afectará aún más la alianza occidental. Por ello, en este plano el gobierno está realizando un sutil desplazamiento de su objetivo principal: ya no se habla de los centros tradicionales de poder mundial como al principio, sino de multiploraismo (Cué y Centenera, 2017). Ante estos cambios, la Canciller Malcorra señaló:

si hubiera un cierre absoluto de los Estados Unidos, que yo no creo que vaya a ocurrir... hoy por hoy no nos representaría un impacto negativo tan grande. Lo que sí haría es representar una falta de oportunidad, porque lo que nosotros vemos en los Estados Unidos es oportunidad... Dicho esto, lo que hagan los Estados Unidos tiene impacto global. Entonces, por ejemplo, no vamos a ver en el corto plazo un avance en el tratado de la UE y los Estados Unidos. Eso es una oportunidad para nosotros para avanzar en el

\footnotetext{
${ }^{13}$ Los acuerdos TTP y TTIP fueron parte de la estrategia de Obama contra China para imponer la agenda OMC Plus demorada desde la cumbre de Cancún en 2003.

${ }^{14}$ Según Arrighi, la demanda norteamericana de bienes y fuentes de financiación para alentar su consumo encontró en China un socio que reemplazó a Japón, pero con una diferencia entre Beijín y Tokio, la primera no es un actor subordinado a Washington. (Arrighi, 2007)
} 
acuerdo entre Mercosur y la UE a una velocidad mayor. Otro ejemplo: Estados Unidos ha dicho claramente que la relación con Asia se va a ralentizar. Ahí tenemos de nuevo toda la cuestión con la Alianza Pacífico, una proyección a Japón, Corea del Sur, Singapur, que es una oportunidad (La cursiva es nuestra, Malcorra, 2016).

Este entusiasmo de la funcionaria contrasta con las percepciones académicas, como por ejemplo de Juan Gabriel Tokatlián, quien ya previamente al triunfo del magnate norteamericano había señalado que "es difícil suponer que en los próximos años no se produzca un decaimiento del multilateralismo, un estancamiento del comercio internacional y un debilitamiento del cosmopolitismo. Advertir esos fenómenos es esencial para entender los condicionamientos que deberá afrontar un ajuste mutuo" (Tokatlian, 2016).

Este desfasaje entre los deseos del gobierno y la conformación de fuerzas en el mundo son una muestra de cómo se desvalorizan las tensiones globales crecientes en la política externa de Macri.

\section{China: el imperio de la necesidad}

Las relaciones con los emergentes, en general, y China, en particular, no escaparon al carácter globalista, ya que no perciben al país como un socio político de ellos para construir alianzas ante de los desafíos de la globalización, sino como un mero proveedor pasivo de alimentos, lo que significa sostener los aspectos más asimétricos de esas vinculaciones.

Está claro que no podríamos esperar ensayos audaces, como los que caracterizaron al kirchnerismo en los últimos años, cuando orientó su estrategia hacia los nuevos polos de poder que se están despuntado en torno a los BRICS, con especial atención en Brasil, Rusia y China, en busca de diversificar nuestras relaciones ${ }^{15}$.

A pesar de estar en un segundo círculo malcorriano, fue evidente que la avidez de inversiones occidentales lo quiebran en favor de Estados Unidos o a Unión Europea, en detrimento de Beijing, como lo indicó Federico Vázquez. El Presidente dijo, en su viaje por Alemania en 2016, "China hizo enormes inversiones en nuestro país. Está muy bien, lo valoro. Pero sentimos que es más fácil el trabajo en común con Europa" (Vázquez, 2016: 4).

Este rechazo se observó en la intención de "revisar" la Asociación Estratégica Integral en lo referido a la construcción de represas en la Santa Cruz y a la cooperación en investigación espacial, por ejemplo (Tomas, 2016). Pero este revisionismo encarado por el gobierno argentino encontró límites en Beijing. Como explica Lewiwkowics, "Macri recibió una noticia amarga si se frena la obra. China pide la devolución inmediata de los 950 millones de dólares desembolsados hasta el momento, corta el fondeo para el Belgrano Cargas y para la hidroeléctrica Chihuidos e incluso tiembla el swap de monedas con el Banco Central" (2016: 8).

En ese sentido, el embajador argentino en Pekín, Diego Guelar, afirmó que fue "una dura negociación" pero que la contraparte obró de "buena fe", bajo argumentos de preservación de medio ambiente. Se redujo la cantidad de turbinas de las represas, en el caso de la Néstor Kirchner: de once a cinco y la Cepernik: de cinco a tres, y con ello cayó el potencial de 1760 MW a 1350. La construcción, no obstante, quedó en manos del consorcio ganador

\footnotetext{
${ }^{15}$ Más que integrarse a este foro de coordinación política de los principales países emergentes, el gobierno de Mauricio Macri está buscando ingresar a la OCDE que agrupa a las economías desarrolladas tradicionales.
} 
de la licitación, encabezado por la empresa estatal china Gezhouba, junto a las argentinas Hidrocuyo y Electroingeniería, esta última vinculada al kirchnerismo (Ortelli, 2016: 42).

Y con respecto a la Estación Espacial que había generado una discusión sobre el carácter militar de esta base de observación lunar, la Canciller en su presentación en el Senado de la Nación defendió la iniciativa frente a la crítica de Fernando Solanas, que señaló la continuidad de aquellos aspectos (HSN, 2016).

El presidente argentino se mostró sensible ante la preocupación norteamericana por el aumento de la influencia China en la región, aunque la primarización de las exportaciones acerca el país a Beijing, lejos de las aspiraciones del presidente conservador y su modelo de inserción económica.

A pesar de las actitudes del gobierno argentino, éste fue invitado al Foro "Una Franja y Una Ruta para la Cooperación Internacional", que reunió a 30 presidentes y mandatarios y buscó directamente con Beijing financiación para el Programa de Obras Publicas 20172019, entre ellas la construcción de dos centrales nucleares, pero Beijín reclamó por las obras paralizadas (por ejemplo, las del Belgrano Cargas y las represas Kirchner y Cepernic en Santa Cruz) ${ }^{16}$.

La profundización del modelo exportador de materias primas, sin embargo, acerca a la Argentina a China, como dijimos, ya que su demanda lo estimula. En el caso de las inversiones ocurre algo parecido, ya que el escepticismo de los centros financieros tradicionales -salvo para la especulación financiera- los mantiene a cierta distancia, observando el proceso político argentino, frente a Beijing, que cuenta con recursos disponibles para garantizar su abastecimiento de productos primarios y energía.

La declaración de Macri en su visita a China de que "los próximos 10 años serán mejor que los 40 anteriores" en la relación bilateral mostró un cambio en su diseño original (EI Cronista, 2017). Este acercamiento, de manera similar al que le ocurrió a Cristina Fernández de Kirchner, buscó reequilibrar el frente externo, pero trae nuevas complicaciones. Cuando la mandataria justicialista firmó aquellos acuerdos, lo hizo para compensar las tensiones crecientes con Washington y Brasilia, producto de la crisis de 2008; esta oportunidad está despojada de los criterios políticos para obtener márgenes de maniobra.

\section{El multilateralismo de Cambiemos}

El Mercosur, principal instrumento de inserción internacional de la Argentina posterior a la crisis de 2001, perdió esa gravitación y quedó reducido a ser la puerta de acceso a la Unión Europea y a la Alianza del Pacífico -la asociación deseada por el gobierno macrista, entre otros acuerdos.

En la marcha hacia el Pacífico encontramos un elemento disociador. Si bien es razonable generar puentes hacia esa área donde está el crecimiento mundial, hacerlo a través del

\footnotetext{
${ }^{16}$ Los ministerios de Energía y Ambiente emitieron una resolución donde se adoptó las recomendaciones de impacto ambiental aprobadas en la Audiencias Pública en el Congreso de la Nación y permitió el avance de la obra, que corrían riesgo de paralizarse e impactar negativamente en otras inversiones chinas como el Ferrocarril Belgrano Cargas, una planta de energía solar en Jujuy y la construcción de una usina en la provincia de Rio Negro y una central nuclear (Simonoff, 2017).
} 
evaporado TPP o sus derivados, que excluyen a la locomotora que impulsaba el área, China, es un error.

Antes de la llegada de Trump, para el gobierno de Macri, el TTP y el TTIP eran las estaciones de llegada y la Alianza del Pacífico y el propio acuerdo con la Unión Europea, las intermedias. Desaparecidos aquellos, éstos se convirtieronen un fin en sí mismos. Por ello se redujo la política exterior a objetivos más modestos: Presidencia del G 20, ingreso a la OCDE, Acuerdos Mercosur Unión Europea y salida de la UNASUR e ingreso al PROSUR.

La realización de la Cumbre del $\mathrm{G}_{20} \mathrm{O}^{17}$ en Buenos Aires se debió al criterio rotativo imperante en esa organización y no a ningún reconocimiento específico ${ }^{18}$. La expresión del documento final que renueva el "compromiso de trabajar juntos para mejorar un orden internacional basado en reglas que sea capaz de responder de manera efectiva a un mundo que cambia rápidamente" $(G 20,2018)$ parecería responder afirmativamente a los deseos de Cambiemos, e incluso llegar a ella lo fue, pero resulta claramente insuficiente, ya que las divergencias de gobernanzas en pugna que venimos describiendo nos llevan a poner en duda dicha expresión.

El ingreso a la OCDE fue otro de los objetivos que se vislumbraron. Esta es una organización formada por países desarrollados que busca sintonizar las políticas públicas de sus miembros con el programa neoliberal bajo la promoción de lo que eufemísticamente se denominan "buenas prácticas". En 2017 el gobierno presentó un plan de acción e hizo el pedido de ingreso, aunque, como evalúo Cecilia Pérez Llana, "Argentina todavía esté fácticamente lejos de alcanzar el estatus de socio de la OCDE" (Pérez Llana, 2016: 9) ${ }^{19}$.

El Acuerdo con la Unión Europea es un tratado de comercio regulado bajo las pautas OMC Plus ${ }^{20}$ con el Viejo Continente, como ya dijimos, primero como un medio para llegar al pacto Transatlántico y, luego de la llegada de Trump, como un fin en sí mismo. Se fundamentó para la primera Canciller del gobierno por ser un área "históricamente muy importante... Y eso es lo que hemos priorizado" (Malcorra, 2016), aunque su relevancia fue decreciendo con los años, producto de las políticas de subsidios y protección paraarancelaria europea en materia agrícola y que son el núcleo de la resistencia expresada por Francia, Polonia y otros países del grupo durante la negociación y posteriormente.

\footnotetext{
${ }^{17}$ El G20 se creó en 1999 como un foro de carácter ministerial con motivo de la crisis asiática e incluía a miembros del G 8 y algunos emergentes, en 2008 fue ascendido al rango presidencial cuando el crack de las "Subprime" se globalizó, pero fue menos efectivos y homogéneo que el consorcio instaurado en 1975 por las principales naciones capitalistas industriales

${ }^{18}$ Tanto Argentina como México y Brasil comparten el grupo 3, al cual le correspondía ser el anfitrión para 2018, el país azteca ya lo había sido con la reunión de Los Cabos de 2012 y el país carioca estaba pasando por una crisis política por el proceso de destitución de la presidenta Dilma Rousseff, cuestiones que dejaban libre el camino para las aspiraciones de Buenos Aires.

${ }^{19} \mathrm{El}$ momento de estar escribiendo existieron dos declaraciones que queremos resaltar: la del Secretario General de la OCDE reclamando ese ingreso como una "política de Estado" (Niebieskikwait, 21 septiembre 2019), y; la del gobierno norteamericano que avaló el ingreso del país, al tiempo que rechazó la del Brasil (Perfil, 10 octubre 2019).

${ }^{20}$ La propuesta OMC Plus intentó marcar una nueva agenda económica internacional impulsada fundamentalmente por los países del G8 y miembros de la tríada (Estados Unidos Europa Occidental y Japón), que fracasó en Cancún y que consistía en la ampliación de la comercialización y la incorporación de normas referidas a la competencia, a movimientos de capitales, propiedad intelectual, desregulación laboral, inversiones y cooperación en rubros como energía, medio ambiente, etcétera.
} 
Luego de dos intentos de anuncios frustrados, finalmente éste se hizo en Osaka en 2019 bajo el título "Acuerdo de Asociación Estratégica Mercosur-Unión Europea”. Este acuerdo fue presentado como algo más que uno en materia comercial, ya que desde el gobierno argentino se señaló que establece "un vínculo político, cultural y económico estratégico y permanente con la Unión Europea" (MRREEyC, junio 2019). Pero esa idea de Europa, como sostuvieron Comini y Sanahuja,

ya no es el actor universalista y cosmopolita del pasado, que pretendía transformar el mundo conforme a sus valores más avanzados, y emerge una UE excepcionalita y defensiva que da prioridad a sus propios intereses y a la protección de su ciudadanía ante un orden internacional en descomposición y un mundo hostil y renuente a responder al modelo europeo (2019: 10).

En esta oportunidad la decisión del bloque conosureño se vio reforzada por la necesidad de anunciarlo antes de la campaña electoral argentina (Neibieskikwait, 7 junio 2019, 4) $y$, desde el lado europeo, por la decisión del Presidente del gobierno español, el socialdemócrata Pedro Sánchez, junto a otros seis jefes de estado (Merkel de Alemania, Costa de Portugal, Rutte de los Países Bajos, Babis de Checa, Karins de Letonia y Lofven de Suecia), quienes elevaron una nota al Presidente de la Comisión Europea, Jean-Claude Juncker, donde señalan que "haga lo posible para culminar ya las negociaciones con el Mercosur" (Idafe, 2019: 25).

Los resultados concretos de la negociación han sido por lo menos desparejos, más allá de la proclamada adhesión a los principios del libre cambio. Nos encontramos con que todos los puntos que los europeos buscaron en el acuerdo fueron logrados ${ }^{21}$, mientras que las cuotas reclamadas desde aquí para productos agrícolas fueron sensiblemente recortadas ${ }^{22}$.

Además, cabe recordar, como lo hizo Julieta Zelicovich en un reportaje de Javier Lewkowicz, que las cuotas no implican libertad de circulación para esos productos, sino que éstos deben adecuarse a las normas productivas europeas (Lewkowicz, julio 2019, 6). Por ese motivo, es un acuerdo de comercio regulado bajo las normas europeas, y no un TLC, y es asimilable a otros ejemplos históricos, ya que se acepta el rol de proveedor de manufacturas de los primeros, poniendo en jaque a las propias, actuales y futuras, pero el nuestro de exportadores de productos agropecuarios también está sujeto a las políticas de subsidios, cuotas y reglamentación sanitaria que restringen esa función en rubros competitivos, como lácteos, vinos, alimentos procesados, etc. ${ }^{23}$

\footnotetext{
${ }^{21}$ En una información que la Comisión Europea difundió para sus empresarios se indicó como oportunidades para: un acceso fácil y privilegiado a un mercado grande y atractivo; la ventaja un acceso privilegiado al Mercosur; el ahorro de impuestos aduaneros; oportunidades para los sectores más competitivos de la Unión Europea; acceso a materias primas a precios competitivos; acceso preferencial a un mercado de servicios, y; lograr igualdad de condiciones para las empresas europeas en compras públicas. (Comisión Europea, 2019) Todos se lograron, salvo el último que tuvo un resultado parcial.

${ }^{22}$ Como ha señalado Lucero, ha habido retroceso en el volumen ofrecido: "La oferta de Europa al Mercosur para el año 2004 fue de 100.000 toneladas de carne. Luego de varios años se había acordado que no habría propuestas menores a los niveles del año 2004, al tiempo que la propuesta en el 2010 del Mercosur fue de abrir el merado a 400.000 toneladas. Lo acordado bajo la gestión de Cambiemos, sin embargo, fueron 99.000 toneladas de carne (Lucero, 2019: 12).
}

${ }^{23}$ Otros rubros en riesgo para los capitalistas locales son los de Obra Pública y Servicios. 
Los ganadores y perdedores estarán determinados, como lo ha señalado Zelicovich, por los elementos que limitan la capacidad de desarrollo del país: la prohibición de retenciones $^{24}$, la reducción arancelaria y las disposiciones fitosanitarias "y obstáculos técnicos a las importaciones que quedan muy limitados, así como también el rol de las empresas del Estado, que son otro elemento de política desarrollista" (Lewkowics, julio, 2019, 6) ${ }^{25}$.

Uno de los problemas más serios para solucionar las asimetrías es de dónde el gobierno conseguirá financiamiento para la "adaptación" de aquellos sectores afectados por el acuerdo, por las tasas elevadas que se pagan aquí, aunque se comprometió a brindar ayuda (Valli, 2019: 27). Sabemos, sin embargo, que:

Los defensores del libre comercio suelen conceder a menudo que algunas personas pueden resultar perjudicadas a corto plazo, pero a continuación argumentan que, a largo plazo todos (al menos la mayoría) van a salir mejor parados. En realidad, no hay nada en la teoría económica que garantice que esto sea así y si, en cambio muchas cosas sugieren lo contrario. Un conocido resultado de Wolfgang Stolper y Paul Samuelson afirma que algunos grupos sufrirán necesariamente perdidas de ingreso a largo plazo a causa del libro comercio (Rodrik, 2011: 271).

Tampoco está claro cómo con los efectos de este acuerdo se logrará "promover el comercio" (Macri, 2019), dado que no existe ningún ejemplo de asociación entre los europeos y unidades políticas periféricas que haya sido beneficiosa para estas últimas. Como ha sostenido Vázquez del Faro, "casi dos décadas de aplicación de este tipo de acuerdos comerciales asimétricos entre la UE y economías emergentes como las de Egipto, Chile, Sudáfrica, Marruecos, Argelia y México dejan un mensaje claro: son un negocio redondo para las empresas y los trabajadores europeos" (2019).

Aunque en realidad hay un problema de fondo, como lo indicó Dani Rodrik hace casi una década; no sólo son estos detalles -nada menores, por cierto-, sino aspectos más generales de una estrategia de inserción como esta, que "centrada en acuerdo comercial para abrir mercados, malgasta mucho capital político y negociador para obtener unas exiguas ganancias económicas. Y aun peor, descuida el principal defecto del sistema, que es la falta de un apoyo generalizado entre la gente corriente" (Rodrik, 2012: 271-272).

Pero volviendo a las acciones que produjo el tratado, en su $54^{\circ}$ Reunión del Consejo de Mercado Común realizada en Santa Fe en julio de 2019, más allá de la euforia reinante por el anuncio, se discutió un esquema de aplicación provisional:

se requiere la aprobación de los cuatro parlamentos nacionales para la entrada en vigor definitiva, aunque en Santa Fe se acordó explorar una vía adhoc apurar los efectos concretos del acuerdo. "Se está evaluando la posibilidad de entrada en vigor provisional de manera bilateral para los estados parte que lo vayan ratificando. Nosotros somos favorables a eso y sabeos que otros países del bloque también" (Barrio, 2019, 44).

\footnotetext{
${ }^{24}$ Las retenciones tienen claramente un doble fin económico, ya que permite separar los precios internos de los externos y, obviamente, fiscal, pero también es un instrumento que permite diseñar una política de desarrollo e inserción internacional (Simonoff, 2009).

${ }^{25}$ Por ese motivo, existen resistencias de sectores industriales a la firma del tratado, pero con la excusa de la pérdida de competitividad ven una oportunidad para llevar adelante la reforma laboral (Stagnaro, 2019: 16).
} 
Al respecto de esta forma de aplicación anticipada, la especialista Julieta Zelicovich planteó lo siguiente:

Esto implica que una vez que el parlamento europeo ratifique la parte comercial, la ratificación en el Mercosur se realizaría por país. Es decir que, si ratifica Brasil, allí entraría en vigor. Esto implica un mecanismo de presión, porque el que no ratifica compite con importados europeos que ingresan al país vecino si obtener beneficios del acuerdo en sus exportaciones (Lewkowics, julio 2019, 6).

La llegada de este Acuerdo llevó a un entusiasmo exagerado por parte del gobierno, que casi inmediatamente anunció otro con EFTA (MRREEyC, agosto 2019) y el inicio de negociaciones con Brasil para un TLC con Estados Unidos (Niebieskilkwait, 5 julio 2019: 8)

Los gobiernos de Mauricio Macri y Jair Bolsonaro y sus contrapartes europeas y norteamericanas saben que la coyuntura política actual ofrece la oportunidad para que los países asuman compromiso de desregulación comercial que pueden ser determinantes para consolidar un perfil de especialización primaria para países de la región (Lewkowicz, agosto 2019: 11).

Incluso aquel sentimiento los llevó a subestimar las señales alarmantes que aparecen del otro lado del Atlántico, como el rechazo austríaco que fue reducido a una mera cuestión electoral (Clarín, 20 septiembre 2019: 10), y la creciente tensión de Francia ${ }^{27}$ e Irlanda con Bolsonaro por la situación de los incendios en la zona amazónica, aunque no se nos escapa que esto puede ser una excusa de otros motivos más profundos (Avignolo, 2019: 35) ${ }^{28}$.

\section{El vecindario a la sombra de los halcones}

En el plano regional el gobierno argentino convivió en sus primeros momentos con la crisis política brasileña por el proceso de juicio político a Dilma Rousseff y su posterior destitución, hasta la llegada de Jair Bolsonaro. A pesar de su discurso claramente misógino, racista y reivindicador de la tortura y de la dictadura militar de 1964 del entonces candidato, y con el fin de generar cierta empatía con él, el Canciller Faurie declaró que se trataba de una opción de centro derecha (Página/12, 30 septiembre 2018: 16) ${ }^{29}$.

Durante el ballotage Bolsonaro declaró que su gobierno iba a tener "una buena relación" y “óptima alianza" con Argentina (Página/12, 26 octubre 2018: 8), aunque el Mercosur quedó en "entredicho", ya que "se ha mostrado partidario de pactar acuerdos bilaterales

\footnotetext{
${ }^{26}$ Como señaló el periodista Carlos Pagni el acuerdo con Washington tiene como dificultad principal la competitividad de las economías mercosurianas con la norteamericana en materia agrícola, pero también otras como el régimen de patentes. (Pagni, 2019, 8)

${ }^{27}$ Fueron significativamente las declaraciones de la nueva embajadora francesa en Argentina, Claudia Scherer-Effosse, quien señaló que como ocurrió con otros acuerdos "hay que esperar, ahora no es el momento de firmarlo." (Niebieskilwait, 24 septiembre 2019, 14)

${ }^{28}$ Una de las condiciones por las cuales los países con mayores intereses agrícolas de Europa aceptaron fue sobre la base de condiciones ambientales que se deben cumplir en el Cono Sur. (Grynspan, 2019, 9)

${ }^{29}$ Incluso fue sorprendente, una vez electo el militar retirado, el Canciller señaló éste posee con Macri una visión coincidente del mundo (Clarín, 7 diciembre 2018, 18)
} 
con cada país y no tanto en bloque" (Marreiro y Lafuente, 2018: 4) y a pesar de las declaraciones del ministro de economía Pablo Guedes en una conferencia de prensa, en donde señaló que ni Argentina ni el Mercosur eran la "prioridad" del nuevo gobierno (Página/12, 30 octubre 2018: 8), cosa que causó conmoción en Buenos Aires y por lo que luego se disculpó (Página/12, 31 octubre 2018: 4).

Aunque el anuncio del acuerdo con la Unión Europea pareciera darles la razón a las autoridades argentinas, expresadas tanto en palabras del Canciller Jorge Faurie como en las del Embajador argentino en Brasil, Carlos Magariños, que descartaban cambios profundos (Gosman, 2018: 3-4), existen fuertes presunciones de que estaríamos asistiendo a un viraje de la estrategia de inserción regional brasileña que se vino sosteniendo desde los años ochenta.

Incluso el acercamiento de Bolsonaro a Trump podría generar dificultades en la estrategia argentina hacia Washington, ya que podría desplazar a Buenos Aires de cierto lugar de privilegio, más retórico que real, que Macri habría logrado gracias a la vacancia generada desde el gobierno de Temer $^{30}$.

Es notable que cuando el ciclo conservador parece cerrarse, y tras el fracaso electoral de Macri, Bolsonaro promovió el adelantamiento de la Reunión del Mercosur en Porto Alegre para principios de diciembre y no a mediados de ese mes, con el objetivo de impedir una rediscusión de la propuesta de reducción de aranceles extrazona en un $50 \%$ por el nuevo gobierno argentino, llegando a proponer su expulsión del Bloque e incluso amenazando salirse de él (Fioriti, 2019) ${ }^{31}$.

La política hacia Venezuela resultó más errática de lo que da cuenta el Presidente en su último discurso en Nueva York (Macri, 2019), ya que la agenda de su primera Canciller, que aspiraba ser Secretaria General de Naciones Unidas, le impidió ajustarse a sus ideas y a las de Washington, cuestión que con Jorge Faurie desapareció.

Para Buenos Aires, la caótica situación política en Caracas, producto del deterioro de su economía, que acentúa el delicado equilibrio institucional entre oficialismo y oposición, tuvo, como indicó Andrés Malamud, el objetivo de "aislar a Venezuela" (Malamud, 2016: 4).

Inicialmente en el plano del Mercosur fue donde estos planteos tomaron una forma más concreta, junto a Paraguay y Brasil, para bloquear el acceso de Venezuela a la presidencia pro témpore, lo que produjo una de sus mayores crisis en toda su historia (Página/12, 5 de octubre de 2016).

Dentro de la reorientación neoliberal del Mercosur es que debe entenderse la suspensión de Venezuela en diciembre de 2016, ya que significaba un obstáculo para el cumplimiento de los objetivos fijados por los gobiernos que representaban el cierre del ciclo progresista. Además, desde la asunción de Trump, el poder de los legisladores republicanos anticastristas, y la consolidación del giro conservador, con los triunfos de Iván Duque en Colombia y Jair Bolsonaro en Brasil, potenciaron la hostilidad hacia el chavismo (Simonoff, 2019a).

\footnotetext{
${ }^{30}$ Es interesante hacer notar que, si bien Macri tiene una agenda positiva con la administración Trump, subsisten puntos conflictivos que no existirían en el caso de nuevo presidente brasileño.

${ }^{31}$ Las corporaciones industriales brasileñas están obligando a revisar estas acciones (Martirena, 2019).
} 
La impugnación por parte del Grupo Lima $^{32}$ del resultado electoral que le permitió a Nicolás Maduro asumir la presidencia de Venezuela y el reconocimiento del Jefe de la Asamblea Nacional, Juan Guaido, como presidente "interino" fueron parte de aquella estrategia tomada desde Washington. ${ }^{33}$

Como un eslabón de ella, la Argentina elevó a la Comisión de Derechos Humanos de la ONU una investigación realizada por el Centro de Orientación de Migrantes y Refugiados, donde se recopilaron denuncias de crímenes cometidos por el régimen chavistas que van "desde violencia sexual hasta ejecuciones extrajudiciales, desapariciones y distinto tipos de torturas" (Beldyk, 29 septiembre de 2019, 25). Pero este informe, sumado al emitido por la Alta Comisionada de Naciones Unidas, Michel Bachelet, le sirvió al gobierno argentino y sus socios del Grupo Lima para "una vez más convocar a la comunidad internacional para utilizar todas las herramientas diplomáticas y jurídicas disponibles para revertir esta situación, para que Venezuela vuelva a ser libre y democrática" (Macri, 2019).

Esta posición claramente intervencionista, típica del neoinstitucionalismo liberal, puso el acento en el derecho a proteger de manera selectiva, ya que se lo aplica solo a los Estados que se apartan del programa de la tríada, aunque es una decisión que atenta contra la estabilidad del sistema interamericano. ${ }^{34}$ Resultó paradójico que, si se buscaba una solución política, el mecanismo idóneo hubiese sido la UNASUR, organismo que el gobierno argentino abandonó en abril de 2019, hecho fundamentado a partir de "una agenda con alto contenido ideológico y muy alejada de sus objetivos iniciales y el desorden administrativo que prevaleció en la organización los últimos tiempos" (MRREEyC, abril 2019).

Desde el año 2009 esa organización funcionó como un ámbito de resolución de diversas tensiones regionales existentes. Por ese motivo, la decisión de salirse de allí y dar una especie de salto al vacío al Foro para el Progreso de América del Sur (PROSUR) es incomprensible, sobre todo si la decisión era que hubiese una salida política en Venezuela ${ }^{35}$.

EI PROSUR es una organización patrocinada por el presidente chileno Sebastián Piñeira, a la que adhirieron rápidamente la mayoría de los gobiernos de derecha de la región (Mauricio Macri de Argentina, Jair Bolsonaro de Brasil, Iván Duque de Colombia, Mario Abdo Benítez de Paraguay y Martín Vizcarra de Perú), y sus objetivos son: avanzar en una zona de libre comercio, coordinar la lucha contra el terrorismo, tráfico de drogas, armas y personas, y potenciar el intercambio de información y experiencias en materia de defensa y ciberataques (Beldyk, 17 marzo 2019, 8).

Resultó evidente la vinculación entre ambos procesos, ya que el PROSUR "materializa" la sepultura de la UNASUR, como lo explicó Juan Gabriel Tokatlián:

Las actitud hasta ahora poco constructiva -en el sentido de la ausencia de un aporte concreto a salidas pacificas- de los participantes del nuevo foro

\footnotetext{
32 Este grupo creado en agosto de 2017 está formado por Argentina, Brasil, Canadá, Chile, Colombia, Costa Rica, Guatemala, Guayana, Honduras, México, Panamá, Paraguay, Perú y Santa Lucía, y ha realizado el seguimiento de la crisis venezolana y coordinado acciones contra el régimen chavista.

${ }^{33}$ Para reforzarla, a principios de marzo de 2019, Mauricio Macri lo recibió en Olivos y en octubre rompió relaciones con el régimen de Maduro.

${ }^{34}$ Un claro ejemplo de ello fue la reacción de Buenos Aires frente a la represión de las movilizaciones contra los gobiernos de Moreno y Piñeira en Ecuador y Chile, respectivamente.

${ }^{35}$ Es necesario dar una solución política, sin excluir a ningún sector en la disputa que permita estabilizar la situación y avanzar en la resolución de la crisis humanitaria que vive Venezuela.
} 
respecto a la angustiosa crisis venezolana, la resignada aceptación sin cuestionamiento a las sanciones materiales impuestos por Washington a Caracas y la desconsideración de alternativas como las sugeridas por el Mecanismo de Montevideo (México y Uruguay más el Caricom), el Grupo Internacional de Contacto para Venezuela (involucrando países de Europa y Latinoamérica) y aún por el Vaticano, insinúan que Prosur está más inclinado a seguir al Norte que mirar al Sur. (Tokatlián, 2019, 20)

Y también explicó la incapacidad de esta elite regional de reconfigurar aquella organización regional, como lo ha sostenido Emanuel Porcelli (2019) de la siguiente manera: "la sobreideologización de la integración regional (en gran parte por la demonización doméstica) lo ha llevado a una incapacidad de apropiarse del proceso, resignificarlo y utilizarlo para sus objetivos regionales como una herramienta válida para los objetivos de la política exterior".

El Grupo Lima se reunió para evaluar, tras el fracaso de Guaidó de tomar el poder en Venezuela, la persistente crisis política y humanitaria que vive ese país, y buscó invitar a Cuba y el Grupo de Contacto Internacional (Alemania, Francia, Italia, Holanda, Portugal, España, Suecia, Reino Unido, Bolivia, Ecuador, Uruguay y Costa Rica) que promueve "elecciones libres" allí. Sin embargo, el grupo reafirmó su "pleno respaldo a las acciones emprendidas durante los últimos días por el pueblo venezolano bajo el liderazgo de Guaidó para restablecer el estado de derecho en Venezuela, de manera pacífica y en respeto al orden constitucional, y lo alientan a perseverar en este esfuerzo" (Perfil, 4 mayo 2019, 33).

En este panorama, la decisión de convocar al TIAR, apoyada desde el gobierno de Macri (Niebieskilkwait, 14 septiembre 2019, 20), y refrendada en Nueva York, a pesar de sostener la exclusión de la intervención militar, dio una señal de peligro que hace dudar sobre lo proclamada actitud mediadora del Grupo Lima, entre Washington y Caracas, cuando comparte el diagnóstico de Trump, pero excluye la opción de intervención bélica, aunque esta parece cada vez más cercana.

Como parte de este proceso de alineamiento con Washington, en julio de 2019, Macri recibió a Mike Pompeo, el Secretario de Estado de Trump, como lo había hecho en mayo con Kimberly Breier, funcionaria del área de América Latina. Al respecto, el canciller de Trump dijo "Argentina se destaca como un socio confiable en nuestros esfuerzos compartidos para restaurar la democracia en Venezuela" (Kiernan, 2019, 2). ${ }^{36}$

Sin embargo, el alejamiento de Bolton por "pasarse de la raya" podría ser un signo de distención:

El enfado de Trump con los asesores que le aseguraban que Maduro tardaría muy poco en caer fue vox populi pocos meses después y Bolton resultó uno de los grandes adalides de la mano dura contra el régimen chavistas. Suyas son también algunas de las declaraciones más belicosas sobre la crisis, como cuando amenazó a Maduro con Guantánamo, y las que no dejaba de poder sobre la mesa la posibilidad de una intervención militar que Trump no deseaba. (Mars, 2019, 4.)

\footnotetext{
${ }^{36}$ Además, se trataron temas como el control de la Triple Frontera y el apoyo norteamericano al país en el FMI por la situación financiera que atraviesa.
} 
Como sabemos, esta salida no fue por diferencias en el objetivo último -el fin del régimen chavista-, sino por la ineficacia de la estrategia llevada adelante por él y que puso a la situación en un callejón sin salida.

\section{La cuestión Malvinas: negocios por soberanía}

El último punto, en relación con nuestro reclamo soberano a Gran Bretaña sobre los archipiélagos australes, al respecto la ministra Malcorra señaló: "En el caso del Reino Unido, sentimos que hay una oportunidad de aprovechar muchas oportunidades que tenemos para hacer negocios, comercio, inversión. Pero también queremos mantener abierto el diálogo con el Reino Unido con el fin de trabajar en una posible solución para este problema de larga data" (Malcorra, 2016).

Estos parámetros coinciden con los establecidos por Juan Carlos Puig cuando señaló que los intentos de concentrarse en la cooperación económica entre Argentina y Gran Bretaña -objetivo principal de esta última-, terminan relegando la cuestión de fondo, la discu-

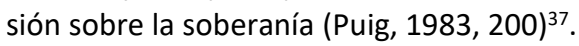

En agosto de 2016 la nueva Premier Británica, Theresa May, envió una carta al presidente Macri en la que abogaba por la negociación de dos temas relegados y de interés británico en la cuestión Malvinas: la ampliación de las frecuencias de vuelos y el "levantamiento de las restricciones para realizar prospecciones de petróleo en el disputado territorio insular" (Tarruela y Rivas Molina, 2016).

Al mes siguiente, estos pedidos fueron tomados en cuenta por el gobierno de Cambiemos, cuando se anunció una Declaración Conjunta argentino-británica, conocida como Foradori-Duncan ${ }^{38}$, donde se trataron los temas reclamados por la Primer Ministra, además de incorporar el inicio del proceso de identificación de los caídos en el cementerio de Darwin y el respeto por la fórmula del paragua de la soberanía (Clarín, 14 septiembre 2016). Como evaluó acertadamente el ex Canciller Jorge Taiana en 2016:

Resulta claro el interés británico en lograr las mejores condiciones para garantizar la explotación de los recursos de las islas, mientras que el gobierno argentino busca una mayor cooperación en algunos temas en los que no queda demasiado claro cuál sería el aporte por parte de Gran Bretaña ni el supuesto beneficio para nuestro país.

Como hace 20 años, se habilitaría la extracción y explotación de recursos naturales que también son objeto de disputa, bajo la promesa de hacerlos conjuntamente -cosa que en el pasado ya se impidió- y se difiere sine die la cuestión de fondo.

El compromiso por despejar esa agenda de los temas de petróleo y pesca, que es una solución a los problemas logísticos y de costos de las explotaciones económicas de nuestros

\footnotetext{
${ }^{37}$ Estrategia no fue novedosa ya que fue seguida en fases de la Revolución Argentina, el Proceso hasta la Guerra de 1982 y la presidencia de Menem.

${ }^{38}$ Por los apellidos de los dos viceministros que suscribieron el documento.
} 
recursos para los británicos ${ }^{39}$, pareciera desarrollarse al margen de ciertos eventos positivos, como la confirmación de la ampliación de nuestros límites marítimos y el Brexit.

Aunque el territorio en disputa está exceptuado, el reconocimiento de la Comisión de Límites de la Plataforma Continental de las Naciones Unidas de la incorporación de 1.633 kilómetros cuadrados, un $35 \%$ de su superficie marítima, ha sido un gran logro para el criterio de integridad territorial sostenido por Buenos Aires en la disputa (Clarín, 23 marzo 2017).

El resultado del referéndum para la salida británica de la Unión Europea fue otra noticia favorable para esta cuestión, como lo ha indicado Roberto García Moritán, ya que dificulta el acceso de su producción pesquera a la UE (un 73\%) y representa el $60 \%$ de la dimensión económica isleña (García Moritán, 2016).

Estas limitaciones económicas no solo generarían oportunidades en la cuestión, sino también desde el punto de vista diplomático. Por ejemplo, la Unión Europea consideró la disputa entre España y el Reino Unido por el peñón de Gibraltar como una "cuestión colonial", cuestión que podría marcar una nueva perspectiva por parte de Bruselas en otras disputas, como la de Malvinas (García Moritán, 2019 febrero, 12). En el caso del reclamo español por Gibraltar, el Brexit fue aprovechado por Madrid, como lo destacó García Moritan: "Quizás el mayor éxito de la diplomacia española es haber hecho de la cuestión Gibraltar un tema relevante en el proceso de salida del Reino Unido de la Unión Europea" (García Moritán, abril 2019, 20) ${ }^{40}$.

Aquí existe una diferencia notable con la Argentina, ya que para el Canciller Faurie:

Sera el ritmo y necesidades del Brexit. Si bien los isleños no tienen la menor confianza en los argentinos, podrían comenzar a cambiar de actitud "si Argentina termina con las sanciones económicas que impuso el gobierno de Kirchner". El segundo punto sería "considerar que los isleños existen, que somos personas e importamos", como dice el ex concejal isleño Mike Summers. (Clarín, 24 julio 2019, 5)

En varios medios argentinos el Canciller Faurie declaró que los isleños "sientan que pueden llegar a Argentina (sic) para educarse, para atenderse en temas de salud y para hacer comercio". Para el Ministro, esta estrategia está destinada a "crear confianza para la integración económica, comercial y la participación de las inversiones británicas en las oportunidades que ofrece la Argentina en materia de energía, infraestructura, minería, turismo y en el sector agropecuario" (Faurie, octubre 2017, 12).

El Canciller defendió el curso de acción seguido en la Cámara de Diputados, incluso llegó ambiguamente a calificar a los habitantes de las islas como "pueblo", algo que el país históricamente rechaza por considerarlos población implantada (Jorquera, 2018, 2).

\footnotetext{
${ }^{39}$ Para ello la canciller Malcorra utilizó la expresión "remoción de obstáculos" para graficar el accionar del gobierno, cuestión que mereció una fuerte crítica, como se observó en su comparecencia ante la Cámara de Senadores en octubre de 2016 (HSN, 2016).

${ }^{40}$ Unos meses después el mismo Embajador precisó cuáles eran las dificultades que el Brexit genera para las posesiones británicas de ultramar: "La duda es si Londres estará en condiciones de contribuir eficazmente al universo de necesidades de la mayoría de las colonias y las ocho bases militares que posee en el extranjero. Este panorama podrá a prueba la capacidad financiera como, entre otros, la logística británica, tanto militar como civil, para seguir manteniendo una presencia global extendida. El ex canciller Willan Hague ya había advertido que el Brexit podría acelerar la desintegración de los últimos vestigios coloniales" (García Moritán, septiembre de 2019, 23).
} 
En diciembre de 2016, ambos gobiernos anunciaron el inicio de las tareas de identificación de los soldados sepultados en el Cementerio de Darwin en la isla Soledad, pero como señala Carlos Biangardi tanto en la declaración conjunta de agosto como en el protocolo con Cruz Roja:

El gobierno argentino (...) salva la responsabilidad de los británicos por la violación de las prácticas operacionales en relación con el tratamiento de los restos humanos y de la información sobre los fallecidos, asume la corresponsabilidad de identificar a sus muertos, continúa admitiendo que una entidad privada se encuentre obligada al mantenimiento de un Cementerio de Guerra en territorio ocupado por las fuerzas armadas del adversario, las que están obligadas a cuidarlo en cumplimiento de los Convenios de Ginebra, y lo presenta como un éxito de su diplomacia. (Biangardi, 2017)

A fines de 2017 se avanzó en la identificación de 88 tumbas de las 123 sin identificación que se encontraban en el Cementerio de Darwin, pero resulta preocupante cómo el problema de fondo -la discusión sobre la soberanía de las islas- continúa encapsulado en esta remake de los fundamentos de la fracasada política de seducción de los años noventa.

Las autoridades británicas manifestaron a lo largo de 2018 y en varias oportunidades su queja por la falta de avance de los Acuerdos Foradori-Duncan para "remover los obstáculos" a los vuelos hacia el archipiélago, y permitir el desarrollo del comercio, navegación, pesca e hidrocarburos de las Islas.

Las negociaciones para la realización de un segundo vuelo semanal estaban paralizadas desde julio de 2019, el único impedimento para las autoridades coloniales británicas fue que este no realizara escala en Argentina. El propio Canciller Faurie declaró al respecto en una entrevista al diario Clarín que:

Estamos analizando tener una mayor conexión aérea, que facilite la vinculación entre el continente y las islas." (Faurie, octubre 2019, 12) En noviembre el gobierno británico lo confirmó, partiría desde Sao Paulo, con una escala mensual en Córdoba por parte de la empresa Latam. El gobierno argentino por su parte declaró que este vuelo se enmarcaba en la Declaración Conjunta de 1999 y que tiene como objetivo contribuir a un "proceso gradual de construcción de confianza. (Niebiskikwait, 2018 noviembre, 17)

Producto del Acuerdo Foradori-Duncan, en noviembre de 2019 se reunió en Londres el Subcomité Científico de la Comisión de Pesca del Atlántico Sur (CPAS). Allí se trataron tema de cooperación científica para la conservación de los recursos pesqueros en el Atlántico Sudoccidental, pero está claro que, como viene ocurriendo en varios asuntos vinculados a Malvinas y como señaló Jorge Arguello: “en esa 'mesa de diálogo bilateral' progresan solo las iniciativas de una de las partes, la británica, necesitada de respuestas económicas para las islas que Londres ya no puede sostener, como antaño, por su propia y traumática coyuntura" (Arguello, 2019, 40).

Ante la requisitoria periodística, y dada la similitud con Malvinas, la Cancillería argentina fue consultada si iba a utilizar el recurso de solicitar una opinión consultiva a la Corte Internacional de Justicia (CIJ), frente a la disposición de esta sobre la cuestión de Chagos, en la cual Gran Bretaña sentenció a abandonar el archipiélago a favor de la República de Mauricio a principios de año, el titular del Palacio San Martín lo descartó (Niebiesklkwiat, 3 abril 2019, 11). 
Esta decisión de la CIJ sobre Chagos fue reforzada por la Asamblea General de Naciones Unidas, la cual se hizo eco de esta medida y votó por 116 votos a favor, 6 en contra (Gran Bretaña y Estados Unidos, entre otros) y 56 abstenciones, con una resolución que le exige a Londres el retiro del archipiélago del Océano Indico (Página/12, 24 mayo 2019, 16). Los británicos indicaron su oposición a cualquier tipo de acción judicial por Malvinas y Gibraltar, a pesar de resaltar la buena relación existente con los países demandantes (Niebiesklkwiat, 24 mayo 2019, 19).

Como parte de su estrategia de cooperación económica, la Secretaria de Energía argentina adjudicó áreas de explotación petrolera en el área de Malvinas a 13 compañías (Exxonmobil, Qatar Petroleum, Tullow Oil, Pluspetrol, Wintershall, Equinor, YPF, ENI, Mitsui, Tecpetrol, Total Austral y BP), algunas de ellas vinculadas a los kelpers, según informó el OETEC (Observatorio de la Energía, Tecnología e Infraestructura para el Desarrollo) a través del diario Página 12 (Página/12, 18 mayo 2019, 16-17). Con ello, según su director Federico Bernal, “Macri consolida la ocupación británica del Atlántico sur" (Página/12, 18 mayo 2019, 17).

Días después el OETEC precisó esa denuncia al indicar que de las 7 áreas adjudicadas a Equinor ${ }^{41}$, "dos de ellas se ubican en la Cuenca de Malvinas Oeste", además que el "municipio de Rio Grande presentó un amparo colectivo para frenar el beneficio a empresas vinculadas al ilegítimo gobierno británico en Malvinas" y hará lo mismo "la gobernación fueguina y el municipio de Ushuaia" (Página/12, 23 mayo 2019, 12).

\section{Conclusiones}

La apuesta por la UE --laramente un actor secundario frente a Washington y Beijingnos lleva a preguntarnos sobre la oportunidad de este acuerdo en el medio de una guerra comercial lanzada por Donald Trump contra China. Estas negociaciones, junto al ingreso a la OCDE y diferenciándose del clima proteccionista imperante, son cómo el gobierno macrista supone el "retorno" al mundo.

Para esta gestión el Mercosur tuvo un valor de "puente" a los acuerdos OMC plus. La derecha conservadora argentina lo consideró como una atadura de nuestra libertad de vincularnos con la triada occidental, por ello sus referencias fueron considerarlo como parte del "aislamiento". Nunca se sintieron cómodos con él y prefieren la fuga hacia el Pacífico con Colombia, Chile, Perú y México.

El mundo es un lugar complejo al que debemos entender no con fórmulas de marketing electoral, sino con un análisis riguroso que nos permita determinar nuestras capacidades para poder aprovechar oportunidades reales y no ilusorias y sin ninguna evidencia empírica.

La crisis de la pretensión de constituir un orden internacional de signo neoliberal nos lleva a pensar que existe una gran incógnita sobre si el optimismo del gobierno macrista en torno al multilateralismo resulta razonable y racional en un marco de creciente disputa entre las dos principales economías mundiales, el ascenso de fórmulas extremistas en los gobiernos de los países centrales a los cuales ha sido sensible y un retroceso generalizado de aquel en el ámbito internacional.

\footnotetext{
${ }^{41}$ Según Federico Bernal, Anne Drinkwatter "actual miembro del directorio de la empresa Equinor, tiene vinculación directa con el gobierno colonialista isleño" (Página/12, 23 mayo 2019, 12).
} 
Las estrategias internacionales de las unidades políticas deben fijarse y realizarse de acuerdo a un análisis racional que permita determinar los marcos globales y las capacidades propias para su ejecución, no por una expresión de deseo.

\section{Bibliografía}

Arrighi, G. (2007). Adam Smith en Pekín. Orígenes y fundamentos del Siglo XXI. Madrid, España: Akal.

Arguello, J. (Marzo de 2019). “Malvinas una gran oportunidad" en Perfil, 3 de marzo de 2019, p. 40.

Avignolo, M. L. (2019). “Francia e Irlanda critican a Bolsonaro y peligra el acuerdo UE-Mercosur". Clarín, 24 de agosto de 2019, p. 35

Banco Mundial. (2018). Comercio de mercaderías (\% del PBI). Washington. Recuperado de: https://datos.bancomundial.org/indicador/TG.VAL.TOTL.GD.ZS?locations $=$ AR\&view $=$ chart

Barrio, F. (2019). "Nuevo Mercosur: entre la apertura y cuentas pendientes". Perfil, 20 de julio de 2019, pp. 44-45.

Beldyk, M. (2019). “De Unasur a Prosur: Argentina se suma a la creación de un Alca sudamericano". Perfil, 17 de marzo de 2019, p. 8.

Beldyk, M. (2019). "Las denuncias de lesa humanidad contra Madura, rumbo a La Haya”. Perfil, 29 de septiembre de 2019, p. 25.

Biangardi Delgado, C. A. (2017). Se debe actuar con suma prudencia con las medidas que se tomen en el futuro con respecto al Cementerio Argentino de Darwin. Opiniones en el IRI. Febrero de 2017, recuperado de: http://www.iri.edu.ar/wp-content/uploads/2017/02/opiniones-en-el-iri-cementerio-darwin-biangardi.pdf.

Busso, A. (2017). El rol de los Estados Unidos en el diseño de política exterior del gobierno de Mauricio Macri. Conceptos básicos para su análisis. Anuario 2017. Recuperado de: http://www.iri.edu.ar/wp-content/uploads/2017/09/A2017amnorArtBusso.pdf

Busso, A., Actis, E. y Novello, M. R. (2017). “La geometría de la Política Exterior Argentina (1989-2015). Fin del diseño triangular e irrupción de un nuevo vértice: las relaciones con Estados Unidos, Brasil y China". En: Busso, A. (Coord.) Modelos de desarrollo e inserción internacional: aportes para el análisis de la política exterior argentina desde la redemocratización: 1983-2011, actores y temas de agenda, T2. Rosario, Argentina: UNR Editora. Editorial de la Universidad Nacional de Rosario, pp. 11-51.

Cervo, A. (2003). Política exterior e relações internacionais do Brasil: enfoque paradigmático. Revista. Brasileña de Política Internacional. 46, (2), pp. 5-25.

Clarín. (2016). El comunicado conjunto entre Argentina y Reino Unido completo. Clarín, 14 de septiembre de 2016. Recuperado de: https://www.clarin.com/politica/comunicado-argentina-reino-unido-completo_0_SygWaNvn.html 
Clarín. (2017). La ONU aprobó la ampliación de la plataforma continental argentina. 23 de marzo de 2017, p. 16.

Clarín. (2017). Mauricio Macri volvió a cruzar a los K: “Éramos uno de los tres países más aislados del mundo". 21 de septiembre de 2017, p. 10.

Clarín. (2018). Mauricio Macri: “El riesgo país sube porque el mundo cree que los argentinos quieren volver atrás". 25 de abril de 2018, p. 5.

Clarín. (2018). Entrevista con el canciller argentino Jorge Faurie: "La visión que tiene Jair Bolsonaro resulta coincidente con la de Mauricio Macri". 7 de diciembre de 2018, p. 18.

Clarín. (2019). “Temor en Malvinas por el cambio de Premier y el divorcio de la Unión Europea". 24 de julio de 2019, p. 5.

Clarín. (2019). “Austria vetó el acuerdo Mercosur-Unión EU, pero el Gobierno minimizó la decisión". 20 de septiembre de 2019, p. 10

Comisión Europea. (2016). Comprehensive Free Trade Agreement with Mercosur Potential gains for the EU. Recuperado de: www.trade.ec.europa.eu/doclib/docs/2016/may/tradoc 144559.pdf

Cué, C. y Centenera, M. (2017). "La cumbre de la OMC termina en fracaso por el efecto Trump". El País, 15 de diciembre de 2017, p. 6

Cué, C. y Jiménez, C. (2015). “Macri busca el apoyo de Brasil para cambiar la política latinoamericana. El País, p. 4.

Di Natale, M. (2016). “Macri busca apoyo externo y de las FF.AA: para combatir el narcotráfico" en La Nación, 8 de Agosto de 2016, rescatado de: http://www.lanacion.com.ar/1925857-macri-busca-apoyo-externo-y-rde-las- ffaa-para-combatir-el-narccotrafico.

Donnan, S. (2017). "Trump cuestiona a la OMC y le provoca una crisis de identidad". El Cronista, 11 de diciembre de 2017. Recuperado de: https://www.cronista.com/financialtimes/Trump-cuestiona-a-la-OMC-y-le-provoca-una-crisis-de-identidad20171211-0014.html.

El Cronista. (2017). "Macri prometió que Argentina será el supermercado del mundo". El Cronista, 17 de mayo de 2017. Recuperado de: https://www.cronista.com/economiapolitica/Macri-prometio-que-Argentina-sera-el-supermercado-del-mundo20170517-0057.html

El Día (2016). Macri y sus 100 días en la rosada "terminamos con el aislamiento". El Día, 20 de marzo de 2016. Recuperado de: http://www.eldia.com/el-pais/macri-y-sus100-dias-en-la-rosada-terminamos-con-el-aislamiento-123284.

Faurie, J. (2018). "La inserción inteligente". Clarín, 26 de febrero de 2018, p. 25.

Faurie, J. (2018). "Los isleños pueden venir a atenderse y hacer negocios". Clarín, 25 de octubre de 2018, p. 12.

Ferrer, A. (2016). "El regreso del neoliberalismo". Le Monde Diplomatique, Año XVII, N²01, Buenos Aires, Capital Intelectual, marzo de 2016, pp. 4-7 
Fukuyama, F. (1990). ¿El fin de la Historia? Babel. Revista de libros. Año II, № 14, pp. 22-30.

G20. (2018). "Leaders' declaration: Building consensus for fair and sustainable development", recuperado de: www.g20.org/sites/default/files/declaracion_de_lideres_de_buenos_aires.pdf

García Moritán, R. (2016). “Una nueva oportunidad para Malvinas”. Clarín, 24 de junio de 2016, recuperado de: http://www.clarin.com/mundo/nuevaoportunidadMalvinas 0 1601240034.html.

García Moritán, R. (2019a). "El Brexit, Gibraltar y una solución que dejó fuera a las Malvinas". Clarín, 4 de febrero de 2019, p. 12.

García Moritán, R. (2019b). "El Brexit, Gibraltar y un giro diplomático con final incierto". Clarín, 7 de abril de 2019, p. 20.

García Moritán, R. (2019c). "El Brexit, las 14 colonias británicas y Malvinas". Clarín, 4 de septiembre de 2019, p. 23.

Ginsberg, L. y Gitter, P. (2019). “Atentado a la AMIA: ¿verdad y justicia... o memoria?” Clarín, 17 de junio de 2019, p. 23.

Gosman, E. (2018). “Argentina descarta cambios en la relación con el Brasil de Bolsonaro y en el Mercosur". Clarín, 30 de octubre de 2018, pp. 3-4.

Grupo Consenso. (2015). Reflexiones sobre los desafíos externos de la Argentina: Seremos afuera lo que seamos adentro. Primer Documento. Buenos Aires, Consejo Argentino de Relaciones Internacionales. Recuperado de: http://www.cari.org.ar/pdf/documento_grupoconsenso.pdf.

Grynspan, Rebeca. (2019). "Acuerdo UE-Mercosur: un poderoso mensaje". Negocios, 7 de julio de 2019, p. 9.

Honorable Senado de la Nación. (2016). “Reunión de la Comisión de Relaciones Exteriores y Culto", Buenos Aires, Publicación de la Dirección General de Taquígrafos, 5 de octubre de 2016.

Honorable Cámara de Diputados de la Nación. (2018). Reunión de la Comisión de Relaciones Exteriores y Culto: Exposición del Señor Canciller Doctor Jorge Faurie, Buenos Aires, Argentina: Publicación de la Dirección General de Taquígrafos. Recuperado de: https://www.diputados.gov.ar/comisiones/permanentes/creyculto/reuniones Lvt/vtcom.html?id=1779.

Fioriti, Santiago. (2019) "El vice de Brasil viajará a la asunción de Fernández, pero la tensión no cede". Clarín, 6 de noviembre de 2019, 6.

Idafe, Martín. (2019). “El Presidente español pide que se acelere el acuerdo entre la UE y el Mercosur". Clarín, 22 de junio de 2019, p. 25.

Ikemberry, J. (2018). "La crisis del orden liberal mundial. Anuario CIDOB. Barcelona, España: CIDOB". Rescatado de: http://anuariocidob.org/avance-la-crisis-del-orden-liberal-mundial/.

Indec. (2019). Intercambio Comercial Argentino. Buenos Aires: Indec. Recuperado de 
https://www.indec.gob.ar/indec/web/Nivel4-Tema-3-2-40

Jorquera, M. (2018). “Canciller en problemas”. Página/12, 30 de octubre de 2018, 2.

Joseph, J. (2011). “Governmentality of What? Populations, States and International Organizations". En: Kiersey, N. y D. Stokes. Foucault and International Relations. New Critical Engagements. New York, Routledge, pp. 51-65.

Kiernan, S. (2019). “Cómo restaurar las relaciones carnales”. Página/12, 20 de julio de 2019, pp. 2-3.

Kollman, R. (2019). "Macri le regla un decreto al amigo americano". Página/12, 18 de julio de 2019, pp. 2-3.

Lamiral, C. (2018). “Argentina perdió el 60\% de sus exportadoras desde 2006”. Ámbito. 21 de agosto de 2018. Recuperado de: https://www.ambito.com/argentina-perdioel-60-sus-exportadoras-2006-n4031216.

Lewkowics, J. (2015). "Socios con la potencia económica mundial” en Página/12, 1/ de febrero de 2015, 18-19.

Lewkowics, J. (2016). "Las represas salen a flote". Página/12, 19 deabril de 2016, pp.18-19.

Lewkowicz, J. (2019). "El estado va a perder margen de maniobra”. Página/12, 25 de julio de 2019, 6.

Lewkowicz, J. (2019). “Estados Unidos ajusta las riendas". Página/12, 2 de agosto de 2019, 11.

Lucero, J. C. (2019). “Integración desequilibrada”. Página/12, 29 de julio de 2019, 12.

Macri, M. (2017). Discurso del presidente Mauricio Macri en la apertura del $135^{\circ}$ período de sesiones ordinarias del Congreso de la Nación Argentina. Casa Rosada. Buenos Aires, Argentina. Recuperado de: http://www.casarosada.gob.ar/informacion/discursos/38791-discurso-del-presidente-mauricio-macri-en-la-aperturadel-135-periodo-de-sesiones-ordinarias-del-congreso-de-la-nacion-argentina.

Macri, M. (2019). Mensaje del presidente Mauricio Macri en la $74^{\circ}$ Sesión de la Asamblea General de la ONU. Nueva York, 24 de septiembre de 2019, recuperado de: https://www.casarosada.gob.ar/informacion/discursos/46315-mensaje-delpresidente-mauricio-macri-en-la-74-sesion-de-la-asamblea-general-de-la-onu.

Malcorra, S. (2016). Argentinian Foreign Policy under Mauricio Macri. The Future of Argentina. A Conversation with.... Council on Foreign Relations Events, Washington, EE.UU. Recuperado de: http://www.cfr.org/argentina/argentinian-foreign-policy-under-mauricio-macri/p37519

Malamud, A. (2016). “Alianza del Pacífico vs. Mercosur: ¿guerra o marketing?” El Estadista, 29 agosto, 2016, p. 4.

Mars, A. (2019). "Trump critica la actitud radical de Bolton sobre Venezuela". El País, 12 de septiembre de 2019, p. 4.

Marreiro, F. y Lafuente, J. (2018). El 'Brasil primero' del ganador abre incertidumbres en la política exterior. El País, 29 de octubre de 2018, p. 4.

Martirena, F. (2019). "Brasil no bajará arancel externo de forma unilateral”. BAE Negocios. 
Recuperado de: https://www.baenegocios.com/economia-finanzas/Brasil-nobajara-arancel-externo-en-forma-unilateral-20191103-0064.html

Ministerio de Relaciones Exteriores y Culto. (2019). La Argentina se retira de la UNASUR. Información para la Prensa $N^{\circ}:$ 145/19. Buenos Aires, 12 de abril de 2019, rescatado de: https://www.cancilleria.gob.ar/es/actualidad/noticias/la-argentina$\underline{\text { se-retira-de-la-unasur }}$

Ministerio de Relaciones Exteriores y Culto. (Junio de 2019). Acuerdo de Asociación Estratégica Mercosur-UE. Resumen informativo elaborado por el gobierno argentino. Buenos Aires, rescatado de: https://www.cancilleria.gob.ar/userfiles/prensa/resumen_acuerdo_mcs-ue_elaborado_por_gobierno_argentino.pdf

Ministerio de Relaciones Exteriores y Culto. (2019). Comunicado conjunto: cierre de las negociaciones Mercosur EFTA. Información para la Prensa N: 334/19. Buenos Aires, 23 de agosto de 2019, rescatado de: https://www.cancilleria.gob.ar/es/actualidad/noticias/comunicado-conjunto-cierre-de-las-negociaciones-mercosur-efta

Niebiskikwait, N. (2018). "Efecto Brexit en Malvinas: los kelpers temen quedar en una posición de debilidad". Clarín, 25 de octubre de 2018, p. 13.

Niebiskikwait, N. (2018). "Confirmado por los kelpers: se podrá viajar a Malvinas desde Córdoba". Clarín, 28 de noviembre de 2018, p. 17.

Niebiesklkwiat, N. (2019). "Argentina desiste de ir a la Corte de La Haya a enjuiciar al Reino Unido". Clarín, 3 de abril de 2019, p. 11.

Niebiesklkwiat, N. (2019). “Antecedente por Malvinas: la ONU ordenó al Reino Unido que se retire de un archipiélago". Clarín, 24 de mayo d 2019, p. 19.

Neibieskikwait, N. (2019). "Mercosur-UE: quieren firmar el acuerdo antes de las elecciones de octubre". Clarín, 7 de junio de 2019, p. 4.

Niebieskilkwait, N. (2019). "Tras el pacto con Europa, Macri y Bolsonaro buscan avanzar en un acuerdo comercial con EEUU”. Clarín, 5 dejulio de 2019, p. 8.

Niebieskilkwait, N. (2019). "El Gobierno se pronunció en contra de una intervención en Venezuela". Clarín, 14 de septiembre de 2019, p. 20.

Niebieskilwait, N. (2019). "Piden que el plan para ingresar a la OCDE se mantenga como política de Estado". Clarín, 21 de septiembre de 2019, p. 14.

Niebieskilwait, N. (2019). "Hay que esperar para el acuerdo Mercosur-UE, no es el momento". Clarín, 24 de septiembre de 2019, p. 14.

Office of the Press Secretary of The White House. (2016). Hoja Informativa: relación entre Estados Unidos y Argentina. Washington, 23 de marzo de 2016, disponible en: https://www.whitehouse.gov/thepressoffice/2016/03/23/hojainformativarelaci\%C3\%B3nentreestadosunidosyargentina, consultado 8/9/2016.

Ortelli, Ignacio. (2016) "Represas: serán más chicas y reducen el impacto ambiental” en Clarín, 7 de mayo de 2016, 42. 
Tenés el mate lleno de infelices ilusiones: la estrategia de inserción internacional del gobierno de Macri (241- 269)

Página/12. (2016). “Mercosur en crisis". Página/12, 5 de octubre de 2016, p. 7

Página/12. (2017). "Malcorra sacó los trapitos al sol”. Página/12, 17 de junio de 2017, p. 5.

Página/12. (2018). “Apenas de centro derecha”. Página/12, 30 de septiembre de 2018, p. 16

Página/12. (2018). "La buena relación entre Macri y Bolsonaro". Página/12, 26 de octubre de 2018, p. 8.

Página/12. (2018). "La prioridad no es el Mercosur". Página/12, 30 de octubre de 2018, p. 8.

Página/12. (2018). "Se arrepintió mucho, poquito, nada". Página/12, 31 de octubre de 2018, p. 4.

Página/12. (2019). “Un ilegal de visita en Olivos. Página/12, 2 de marzo de 2019, p. 12.

Página/12. (2019). “Con permiso para perforar la soberanía”. Página/12, 18 de mayo de 2019, pp. 16-17.

Página/12. (2019). "Con la impronta de los kelpers". Página/12, 23 de mayo de 2019, p. 12.

Página/12. (2019). "Derrota británica en un caso similar a Malvinas". Página/12, 24 de mayo de 2019, p. 16.

Página/12. (2019). “El Grupo de Lima volvió a la carga contra Maduro”. Página/12, 24 de julio de 2019 , p. 14

Página/12. (2019). Argentina, la más vulnerable del mundo". Página/12, 26 de julio de 2019, pp. 2-3.

Pagni, C. (2019). Mercosur y la euforia del comercio libre". El País, 9 de julio de 2019, p. 8.

Pérez Llana, C. (Agosto de 2016). “Argentina en la OCDE”. Le Monde Diplomatique, XVIII, N 206, Buenos Aires, pp. 8-9.

Perfil. (2017). “Netanyahu llega a Argentina y será recibido por Macri”. Perfil, 11 de septiembre de 2017, p. 8.

Perfil. (2019). "El Grupo de Lima quiere suma a Cuba a sus debates". Perfil, 4 de mayo de 2019, p. 33.

Perfil. (2019). "EEUU puso precio al presunto cerebro del ataque". Perfil, 20 de julio de 2019, p. 16.

Perfil. (2019). "Estados Unidos rechaza el ingreso de Brasil a la OCDE y apoya el de la Argentina". Perfil, 10 de octubre de 2019, recuperado de: www.perfil.com/noticias/política/estados-unidos-rechaza-ingreso-brasil-ocde.htlm.

Porcelli, E. (2019). "La incapacidad de resignificar la integración regional.” Diagonales.com, 21 de octubre de 2019, rescatado de: https://diagonales.com/contenido/la-incapacidad-de-resignificar-la-integracin-regional/14422

Puig, J. C. (1983). Malvinas y Régimen Internacional. Buenos Aires, Depalma.

Rodrik, D. (2011). La paradoja de la globalización. Democracia y futuro de la economía mundial. Barcelona, Antoni Bosch. 
Rapoport, M. y Spiguel, C. (2003). “Modelos económicos, regímenes políticos y política exterior argentina". En: Sombra Saraiva, F. (Ed.). Foreign Policy and polical regime. Brasilia: Instituto Brasileño de Relaciones Internacionales, pp. 169-235.

Sanahuja, J. A. y Comini, N. (2018). Las nuevas derechas frente a una globalización en crisis. Nueva Sociedad, mayo-junio 2018, recuperado de: https://nuso.org/articulo/las-nuevas-derechas-latinoamericanas-frente-globalizacion-en-crisis/

Simonoff, A. (2009). Retenciones y Política Exterior. Relaciones Internacionales. Año 18, № 37, pp. 187-210.

Simonoff, A. (2012). "Cinco claves explicativas para la política exterior argentina posterior a la crisis de 2001". En: Morasso, C. y Pereyra Doval, G. (Comp.). Argentina y Brasil: proyecciones internacionales, Cooperación Sur-Sur e integración. Rosario, UNR Editora, pp. 105-131.

Simonoff, A. (2016). El aislamiento como concepto de la política externa argentina. VIII ${ }^{\circ}$ Congreso de Relaciones Internacionales del IRI. La Plata, Argentina: IRI. Recuperado de: http://sedici.unlp.edu.ar/bitstream/handle/10915/57854/Documento_completo.pdf-PDFA.pdf?sequence $=1$

Simonoff, A. (2017). ¿La necesidad tiene cara de hereje? Signos de pragmatismo en el diseño de inserción argentina de la administración de Mauricio Macri. VIII Encuentro del CERPI y VI Jornada del CENSUD “Argentina y América Latina frente al nuevo escenario internacional". La Plata, IRI-UNLP.

Simonoff, A. (2019a). Presentación del Trigésimo Informe Semestral sobre Política Exterior del gobierno argentino (septiembre 2018- marzo 2019): momento de balance y campaña electoral. Revista Relaciones Internacionales. Número 56. Recuperado de: http://www.iri.edu.ar/wp-content/uploads/2019/07/ri56-PEA-0-presentacion.pdf

Simonoff, A. (2019b). "El gobierno tomó una serie de medidas que aumentaron la vulnerabilidad del país". L’Ombelicodel Mondo. Periodismo internacional. Recuperado de: https://ombelico.com.ar/2019/08/19/el-gobierno-tomo-una-serie-de-medidas-que-aumentaron-la-vulnerabilidad-del-pais/

Stagnaro, R. (2019c). "Usan el acuerdo con la UE para impulsar el reclamo de una reforma laboral". Tiempo Argentino, 30 de junio de 2019, p. 16.

Taiana, J. (2016). “Muchos beneficios para el Reino Unido” en Página/12, Buenos Aires, 17 de septiembre de 2016, p. 12.

Tarruela, P. y Rivas Molina, F. (2016) “May propone un acercamiento al Gobierno argentino por Malvinas" en El País, Madrid, 11 de agosto de 2016, disponible en: ttp://internacional.elpais.com/internacional/2016/08/11/actualidad/1470943281_678660.html, consultado el 9/9/16.

Tokatlián, J. G. (2016). “Hacia una relación más madura”. La Nación, 31 de octubre de 2016, recuperado de: http://www.lanacion.com.ar/1951851-hacia-una-relacionmas-madura

Tokatlián, J. Gl. (2019). “Bye Bye Unasur”. Página/12, 22 de marzo de 2019, p. 20 
Tomas, A. (2016). "Mientras gira hacia Occidente, Macri congela los proyectos rusos y chinos". Perfil, 23 de enero de 2016, rescatado de: http://www.perfil.com/politica/Mientras-gira-hacia-Occidente-Macri-congela-los-proyectos-rusos-y-chinos-20160123-0021.html.

Valli, P. (2019). "El financiamiento, talón de Aquiles de la "adaptación" para competir con Europa". Perfil, 7 de julio de 2019, p. 27.

Vázquez del Faro. (2019). “Acuerdo Mercosur-Unión Europea: la negativa experiencia de otras economías emergentes". Observatorio de Coyuntura Internacional y Política Exterior. Rescatado de: https://ocipex.com/acuerdo-mercosur-union-europea-la-negativa-experiencia-de-otras-economias-emergentes/

Walt, S. (2018). The Hell of Good Intentions. America's Foreign Policy Elite and the Decline of U.S. Primacy. Farrar, Straus and Giroux.

Vázquez, F. (2016). "La nostalgia por un mundo que ya no es". Le Monde Diplomatique, XVIII, $\mathrm{N}^{\circ} 206$, Buenos Aires, agosto de 2016, 4-5.

Wainer, A. y Belloni, P. (2019). "El fracaso de la reinserción”. Suplemento económico de Página/12 Cash, 16 de junio de 2019, pp. 4-5. 